\title{
ASSESSMENT OF INFLAMMATORY STATUS IN METABOLIC SYNDROME
}

\author{
NIVESH KRISHNA ${ }^{1}$, ANITHA ROY ${ }^{*}$, SAVITHA G ${ }^{3}$
}

${ }^{1}$ Department of Pharmacology, Saveetha Dental College, Saveetha Institute of Medical and Technical Sciences, Saveetha University, Chennai, Tamil Nadu, India. ${ }^{2}$ Department of Pharmacology, Saveetha Dental College, Saveetha Institute of Medical and Technical Sciences Saveetha University, Chennai, Tamil Nadu, India. ${ }^{3}$ Department of Biochemistry, Saveetha Dental College, Saveetha Institute of Medical and Technical Sciences, Saveetha University, Chennai, Tamil Nadu, India. Email: anitharoy2015@gmail.com

Received: 09 March 2018, Revised and Accepted: 09 April 2018

\section{ABSTRACT}

Objective: The aim of the present study was to assess the level of inflammation in metabolic syndrome (MetS) individuals by estimating C-reactive protein (CRP) in the individuals.

Methods: A total of 60 subjects were selected from those attending the outpatient department of a private hospital and divided into two groups $(\mathrm{n}=30)$ : Group 1 - healthy individuals and Group 2 - individuals with MetS. Informed consent was obtained from the subjects before sample collection. $5 \mathrm{ml}$ of fasting venous blood was collected and centrifuged at $3000 \mathrm{rpm}$ to separate serum, and then, it was analyzed for fasting blood sugar (FBS) by glucose oxidase-peroxidase method, serum triglycerides (TGL) by colorimetric enzymatic method, and serum CRP by Turbilatex method using ERBA CHEM 5 plus analyzer.

Results: Mean body mass index level in control and MetS group is $22.73 \pm 2.14$ and $35.53 \pm 3.57$, respectively. Mean FBS levels in the control group and MetS group are $85.6 \pm 11.59$ and $115.67 \pm 24.52$, respectively. Mean TGL levels in the normal control group and MetS group are $105.63 \pm 30.26$ and

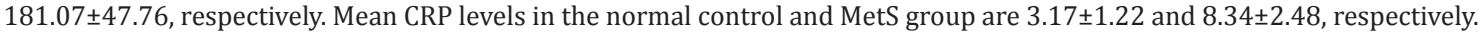

Conclusion: CRP level positively correlated with MetS. Evaluation of CRP can be used as a surrogate marker to assess the inflammatory status of MetS individuals.

Keywords: C-reactive protein, Metabolic syndrome, Disorder, Inflammatory.

(C) 2018 The Authors. Published by Innovare Academic Sciences Pvt Ltd. This is an open access article under the CC BY license (http://creativecommons. org/licenses/by/4. 0/) DOI: http://dx.doi.org/10.22159/ajpcr.2018.v11i7.25744

\section{INTRODUCTION}

The metabolic syndrome (MetS) is a common and a very important public health issue, worldwide. MetS confers a 5 -fold rise in the risk of type 2 diabetes mellitus and 2-fold rise in the development of cardiovascular disease (CVD) over the next 5-10 years [1-3]. MetS is a type of disorder which includes a group of multiple metabolic abnormalities in a person. The World Health Organization and programs including the National Cholesterol Education Program demonstrated that MetS is a constellation of abnormalities which include high blood sugar, high blood pressure, abnormal obesity, high serum triglycerides (TGL), and low high-density lipoprotein levels.

Insulin resistance, visceral adiposity, atherogenic dyslipidemia, endothelial dysfunction, genetic susceptibility, elevated blood pressure, hypercoagulable state, and chronic stress are the several factors which constitute the syndrome. In abnormal obesity, a large quantity of circulating free fatty acids are produced by the upper body adipocytes while an intra-abdominal fat has been positively correlated with the splanchnic free fatty acid levels contributing to liver fat accumulation [4]. Therefore, CVDs and type 2 diabetes are deeply attributed with MetS [5-7]. There is a worldwide prevalence of MetS ranging from $<10 \%$ to as much as $84 \%$, based on the region, urban or rural environment as well as composition of the population [8].

A recent study demonstrates a linear relationship between the inflammatory marker C-reactive protein (CRP) and MetS [9]. Proinflammatory markers are elevated in the case of MetS. The proinflammatory markers which increase in MetS individuals with type 2 diabetes include CRP, fibrinogen, plasminogen activator inhibitor), and cytokines such as interleukin-1 (IL-1 $1 \beta$ ) and IL-6. Increased levels of IL-8 aid in predicting cardiovascular events and mortality in populations affected by MetS-related diseases [10]. Most of the affected individuals are old, obese, and sedentary and have a degree of insulin resistance. Stress is one of the major contributing factors. The official cause of the MetS is under study $[11,12]$. MetS is one of the major risk factors for many neurological disorders [13].

The most common and well-standardized biomarker of inflammation is the CRP. Many studies show that there is an elevated level of CRP in patients with MetS [14]. Recent studies also aid in demonstrating the impairment of insulin signals by CRP $[15,16]$. Basically, CRP is synthesized in the liver in response to the stimulating factors elicited by macrophages and adipocytes.

The function of CRP is the activation of complement system, eliciting phagocytosis by macrophages, which clears necrotic and apoptotic cells and bacteria and gets elevated within $2 \mathrm{~h}$ of the onset of the inflammation and peaks at $48 \mathrm{~h}[17,18]$. Plasma CRP levels are low in healthy individuals [14]. CRP levels above $10 \mathrm{mg} / \mathrm{dl}$ predispose an increased risk of myocardial infarction, ischemic stroke, and peripheral arterial disease $[19,20]$. IL- 6 also gets released in response to elevated CRP levels in obese individuals [21,22]. Since MetS is a cluster of many inflammatory diseases, the aim of the current study was to assess the level of inflammatory marker - CRP in MetS individuals.

\section{METHODS}

Patients were selected from those attending the outpatient department of a private hospital and divided into two groups $(n=30)$ as follows: 
Group I - Normal healthy individuals

Group II - Patients with MetS.

\section{Inclusion criteria}

The following criteria were included in the study:

- Individuals with the age group of 35-55 years

- Individuals with type 2 diabetes mellitus (fasting blood sugar [FBS] $\geq 100 \mathrm{mg} / \mathrm{dl}$ )

- Individual with normal body mass index (BMI) (18.9-24.9) and obese BMI $(\geq 30)$

- $\quad$ Serum TGL levels more than $150 \mathrm{mg} / \mathrm{dl}$.

Exclusion criteria

The following criteria were excluded from the study:

- Individuals with other systemic illness such as cardiovascular disease, renal failure,stroke, and endocrine illness.

- Individuals with acute illness like fever

- Immunocompromised individuals

\section{Sample collection}

Informed consent was obtained from the patient before sample collection. $5 \mathrm{ml}$ of fasting venous blood was collected and distributed in plain collection tubes and centrifuged at $3000 \mathrm{rpm}$ to separate serum, and then, it was analyzed for FBS by glucose oxidase-peroxidase method, serum TGL by colorimetric enzymatic method, and serum CRP by Turbilatex method using ERBA CHEM 5 plus analyzer.

\section{Statistical analysis}

All the data were analyzed using SPSS package. Student t-test analysis was done to find significant difference between the control and study groups. All tests were considered statistically significant at $\mathrm{p}<0.05$ level.

\section{RESULTS}

In the present study, MetS group. Mean BMI level in control and MetS group was $22.73 \pm 2.14$ and $35.53 \pm 3.57$, respectively. Mean FBS levels in the control group and MetS group were $85.6 \pm 11.59$ and $115.67 \pm 24.52$, respectively. Mean TGL levels in the normal control group and MetS group were $105.63 \pm 30.26$ and $181.07 \pm 47.76$, respectively. Mean

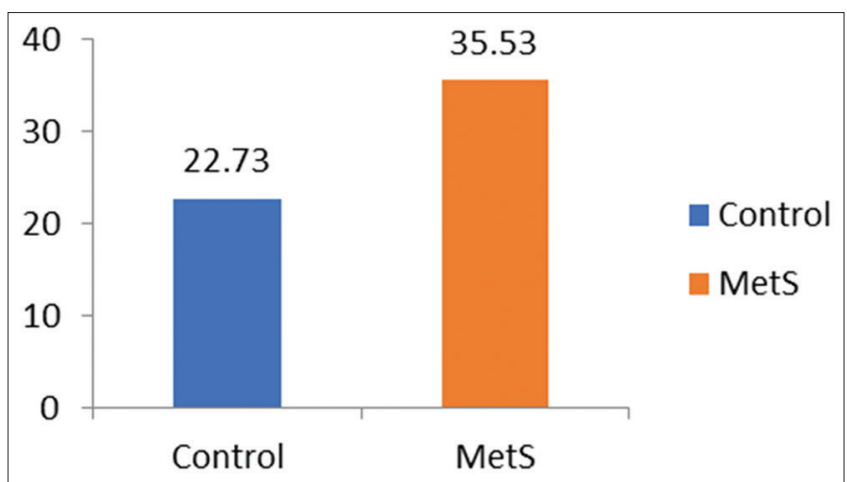

Fig. 1: Mean body mass index values in control and study group

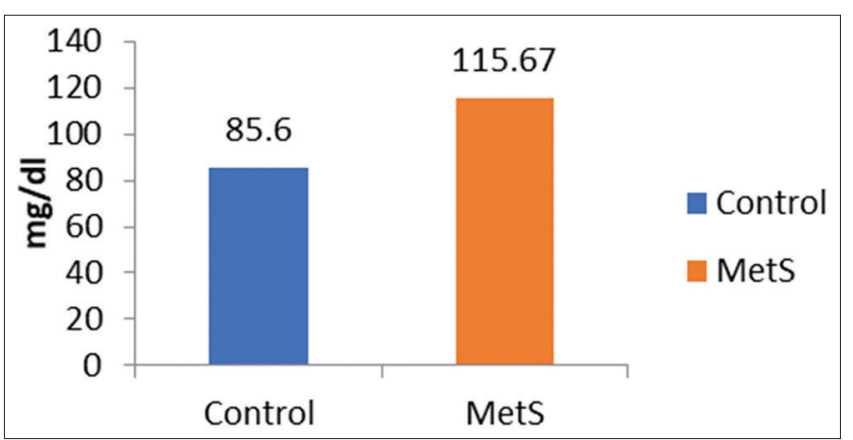

Fig. 2: Mean fasting blood sugar value in control and study group
CRP levels in the normal control and MetS group were $3.17 \pm 1.22$ and $8.34 \pm 2.48$, respectively (Table 1and Figs. 1-4).

\section{DISCUSSION}

Results of the study revealed that there is a significant difference between the mean BMI, FBS, TGL, and CRP levels of control group and MetS group. There is a significant difference between mean BMI, FBS, and TGL levels which indicates proper selection of subjects in both the groups. There is a significant difference between the mean CRP level in both the groups with the $\mathrm{p}<0.00$ level.

Low-grade inflammation is the characteristic feature of the MetS. There are many inflammatory markers to diagnose inflammation, among which CRP is the simplest to diagnose the inflammatory state of the disease. Recent studies proved the CRP levels had a positive correlation with BMI, TGL, glucose, and uric acid. It was also found that subjects with high CRP levels had MetS and were obese [8,23,24]. In certain people, there was an increase in TGL level twice the fold due to MetS [25]. BMI was also found to be a predominant contributor in MetS [26]. There was also a release of IL6 by human subcutaneous adipose tissues which in turn elicits the production of acute phase proteins in the liver. From this, the studies were able to show a significant relationship between CRP and obesity $[27,28]$. The association of periodontitis and MetS is reported in literature [2]. Literature shows scientific evidence of association of inflammatory markers with obesity and diabetes mellitus $[29,30]$.

Table 1: BMI, FBS, TGL, and CRP levels of control and study groups

\begin{tabular}{llll}
\hline Parameters & Mean \pm SD & & \\
\cline { 2 - 4 } & Control & $\begin{array}{l}\text { Metabolic } \\
\text { syndrome }\end{array}$ & p value \\
& $22.73 \pm 2.14$ & $35.53 \pm 3.57$ & $<0.00$ \\
BMI & $85.6 \pm 11.59$ & $115.67 \pm 24.52$ & $<0.00$ \\
FBS (mg/dl) & $105.63 \pm 30.26$ & $181.07 \pm 47.76$ & $<0.00$ \\
TGL (mg/dl) & $3.17 \pm 1.22$ & $8.34 \pm 2.48$ & $<0.00$ \\
CRP (mg/dl) & &
\end{tabular}

BMI: Body mass index, FBS: Fasting blood sugar, TGL: Triglycerides, CRP: C-reactive protein, SD: Standard deviation

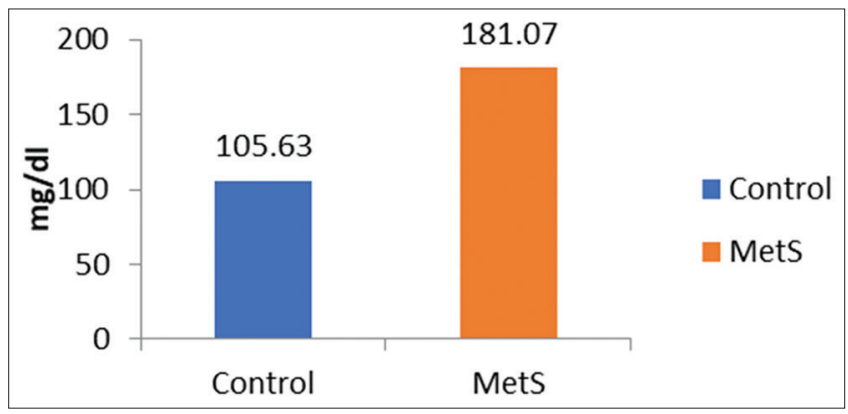

Fig. 3: Mean triglycerides value in control and study group

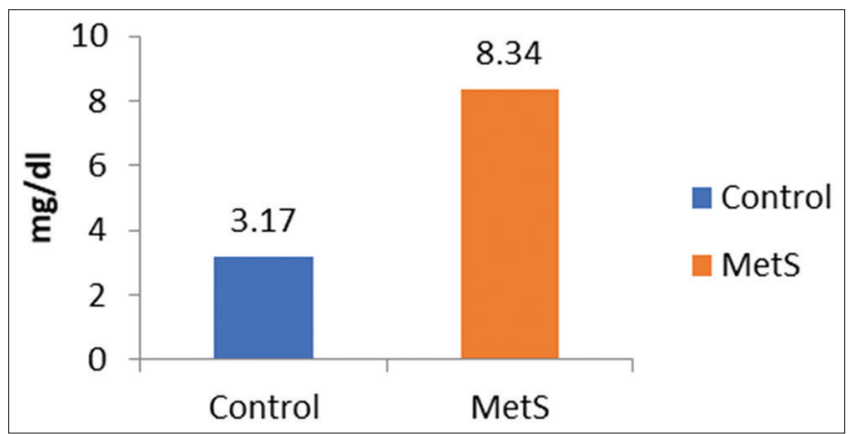

Fig. 4: Mean C-reactive protein value in control and study group 


\section{CONCLUSION}

Emerging laboratory and clinical evidences have provided a strong relationship between the CRP and MetS. Hence, henceforth, the data showed a link between the inflammation, insulin resistance, and components of MetS. To conclude, this study helps to create awareness about CRP levels, to aid in the diagnosis and early prognosis of MetS in obese individuals.

\section{AUTHOR'S CONTRIBUTION}

Nivesh Krishna: Preparation of the manuscript. Anitha Roy: Design and compilation of final manuscript. Savitha G: Methodology and data interpretation.

\section{CONFLICTS OF INTEREST}

The authors declare that there is no conflict of interest regarding publication of this article.

\section{REFERENCES}

1. Alberti KG, Eckel RH, Grundy SM, Zimmet PZ, Cleeman JI, Donato KA, et al. Harmonizing the metabolic syndrome: A joint interim statement of the international diabetes federation task force on epidemiology and prevention; National heart, lung, and blood institute; American heart association; World heart federation; International atherosclerosis society; And international association for the study of obesity. Circulation 2009;120:1640-5.

2. Priyalakshmi S, Sankari M. A review on metabolic syndrome and periodontal disease. IOSR J Dent Med Sci (IOSR-JDMS) 2014;13:1-5.

3. Mounika S, Savitha G. Association of periodontal diseases and metabolic syndrome. Res J Pharm Tech 2015;8:994-6.

4. Miles JM, Jensen MD. Counterpoint: Visceral adiposity is not causally related to insulin resistance. Diabetes Care 2005;28:2326-8.

5. Onat A. Metabolic syndrome: Nature, therapeutic solutions and options. Expert Opin Pharmacother 2011;12:1887-900.

6. Kaur J. A comprehensive review on metabolic syndrome. Cardiol Res Pract 2014;2014:943162

7. Saulo JA. Ursolic acid in experimental models and human subjects: Potential as an anti-obesity/overweight treatment? Cancer 2015;2015:1- 10 .

8. Festa A, D'Agostino R Jr., Howard G, Mykkänen L, Tracy RP, Haffner SM, et al. Chronic subclinical inflammation as part of the insulin resistance syndrome: The insulin resistance atherosclerosis study (IRAS). Circulation 2000;102:42-7.

9. Trøseid M, Seljeflot I, Arnesen H. The role of interleukin-18 in the metabolic syndrome. Cardiovasc Diabetol 2010;9:11.

10. Pollex RL, Hegele RA. Genetic determinants of the metabolic syndrome. Nat Clin Pract Cardiovasc Med 2006;3:482-9.

11. Poulsen P, Vaag A, Kyvik K, Beck-Nielsen H. Genetic versus environmental aetiology of the metabolic syndrome among male and female twins. Diabetologia 2001;44:537-43.

12. Farooqui AA, Farooqui T, Panza F, Frisardi V. Metabolic syndrome as a risk factor for neurological disorders. Cell Mol Life Sci 2012;69:741- 62 .

13. Ridker PM, Hennekens CH, Buring JE, Rifai N. C-reactive protein and other markers of inflammation in the prediction of cardiovascular disease in women. N Engl J Med 2000;342:836-43.

14. Xu JW, Morita I, Ikeda K, Miki T, Yamori Y. C-reactive protein suppresses insulin signaling in endothelial cells: Role of spleen tyrosine kinase. Mol Endocrinol 2007;21:564-73.

15. D'Alessandris C, Lauro R, Presta I, Sesti G. C-reactive protein induces phosphorylation of insulin receptor substrate-1 on ser307 and ser 612 in L6 myocytes, thereby impairing the insulin signalling pathway that promotes glucose transport. Diabetologia 2007;50:840-9.

16. Pepys MB, Hirschfield GM. C-reactive protein: A critical update. J Clin Invest 2003;111:1805-12.

17. Lau DC, Dhillon B, Yan H, Szmitko PE, Verma S. Adipokines: Molecular links between obesity and atheroslcerosis. Am J Physiol Heart Circ Physiol 2005;288:H2031-41.

18. Gabay C, Kushner I. Acute-phase proteins and other systemic responses to inflammation. N Engl J Med 1999;340:448-54

19. Ridker PM, Buring JE, Shih J, Matias M, Hennekens CH. Prospective study of C-reactive protein and the risk of future cardiovascular events among apparently healthy women. Circulation 1998:98:731-3.

20. Koenig W, Sund M, Fröhlich M, Fischer HG, Löwel H, Döring A, et al. C-reactive protein, a sensitive marker of inflammation, predicts future risk of coronary heart disease in initially healthy middle-aged men: Results from the MONICA (Monitoring trends and determinants in cardiovascular disease) Augsburg cohort study, 1984 to 1992. Circulation 1999;99:237-42

21. Maseri A, Biasucci LM, Liuzzo G. Inflammation in ischaemic heart disease. BMJ 1996;312:1049-50

22. Haverkate F, Thompson SG, Pyke SD, Gallimore JR, Pepys MB. Production of C-reactive protein and risk of coronary events in stable and unstable angina. European concerted action on thrombosis and disabilities angina pectoris study group. Lancet 1997;349:462-6

23. Aronson D, Bartha P, Zinder O, Kerner A, Markiewicz W, Avizohar O, et al. Obesity is the major determinant of elevated C-reactive protein in subjects with the metabolic syndrome. Int J Obes Relat Metab Disord 2004;28:674-9.

24. Visser M, Bouter LM, McQuillan GM, Wener MH, Harris TB. Elevated C-reactive protein levels in overweight and obese adults. JAMA 1999;282:2131-5.

25. Sumner AE. Ethnic differences in triglyceride levels and high-density lipoprotein lead to underdiagnosis of the metabolic syndrome in black children and adults. J Pediatr 2009;155:S7.e7-11.

26. Ramdas J, Jella V. Elevated C reactive protein levels in obese individuals with metabolic syndromes. Int J Adv Med 2016;3:162-5.

27. Banks RE, Forbes MA, Storr M, Higginson J, Thompson D, Raynes $\mathrm{J}$, et al. The acute phase protein response in patients receiving subcutaneous IL-6. Clin Exp Immunol 1995;102:217-23.

28. Papanicolaou DA, Wilder RL, Manolagas SC, Chrousos GP. The pathophysiologic roles of interleukin-6 in human disease. Ann Intern Med 1998;128:127-37.

29. El-Wakkad A, El-Morsi Hassan N, El-Zayat SR, Sibaii H, El-Raof SA, El-Masry A. Multiple markers of diabetes in relation to abdominal obesity in obese Egyptian adolescent girls. Int J Pharm Pharm Sci 2012;4:276-81.

30. Al-Biati HA, Sahib AS, Ismail SH. Effects of metformin and glibenclaimide combination in Iraqi obese patients with metabolic syndrome. Int J Pharm Pharm Sci 2014;6:501-3. 